\title{
Pertunjukkan Ketoprak Lakon Pedhut Jatisrana Sebagai Media Pendidikan Karakter
}

\author{
Hari Setiawan, Ani Rakhmawati, dan Atikah Anindyarini ${ }^{3}$ \\ Jurusan Pendidikan Bahasa dan Sastra Daerah, Pascasarjana, Universitas Sebelas Maret, Surakarta \\ ${ }^{1}$ harisetiawan@student.uns.ac.id
}

\begin{abstract}
Pertunjukkan ketoprak merupakan suatu pertunjukkan dengan menampilkan cerita kehidupan masyarakat Jawa yang banyak mengandung pesan dan nilai karakter yang sangat berguna untuk kehidupan sehari-hari dengan dikemas dalam bentuk dialog dan adegan. Pendidikan karakter berguna untuk mengatur dan membina karakter masyarakat khususnya para remaja. Hal tersebut dikarenakan banyaknya karakter perilaku yang menyimpang dan memprihatinkan yang ditunjukkan oleh para remaja. Penelitian ini bertujuan untuk menganalisis nilai pendidikan karakter pada pertunjukkan ketoprak lakon Pedhut Jatisrana sebagai sarana dan media pendidikan karakter. Adapun sumber data pada penelitian ini dengan menyimak dan mengamati langsung video dokumentasi pertunjukkan ketoprak lakon Pedhut Jatisrana. Teknik pengumpulan data pada penelitian ini menggunakan analisis dokumentasi video pertunjukkan ketoprak lakon Pedhut Jatisrana. Adapun analisis data menggunakan pengamatan adegan dan dialog pada pertunjukkan ketoprak Pedhut Jatisrana. Pada hasil penelitian ditemukan adanya nilai pendidikan karakter yang dikemas dalam sebuah dialog pada pertunjukkan ketoprak Pedhut Jatisrana karya Bondan Nusantara tersebut. Adapun nilai pendidikan karakter yang ditemukan yaitu karakter peduli sosial, jujur, cinta damai, kerja keras, cinta tanah air, religius, dan rasa ingin tahu yang terdapat pada dialog-dialog pertunjukkan ketoprak tersebut. Adapun nilai-nilai pendidikan karakter berguna dan relevan sebagai sarana dan media pendidikan karakter untuk masyarakat saat ini.
\end{abstract}

Kata kunci: ketoprak, media pendidikan karakter

\section{Performance of Ketoprak Pedhut Jatisrana as Character Education Media}

The ketoprak show is a show by presenting the life stories of Javanese people which contain many messages and character values which are very useful for daily life by being packaged in the form of dialogue and scenes. Character education is useful for managing and building the character of society, especially teenagers. That is because there are many distorted and apprehensive behavioral characteristics shown by teenagers. This research is aimed to analyze the value of character education in the performance ketoprak of Pedhut Jatisrana as a means and media of character education. The source of the data in this study was by checking out and observe the firsthand video documentation of the performance of ketoprak Pedhut Jatisrana. Data collection techniques in this study used a video documentation analysis of the performance of ketoprak Pedhut Jatisrana. The data analysis uses the observation of the scene and dialogue on the performance ketoprak Pedhut Jatisrana. In the results of the study it was found that there was value of character education which is packaged in a dialogue at the Ketoprak of Pedhut Jatisrana by Bondan Nusantara. The value of character education that was found is the character of social care, honest, love peace, hard work, love the motherland, religious, and the curiosity that exists in these ketoprak performance dialogues. The values of character education are useful and relevant as a means and media for character education for today's society.

Keywords: ketoprak, character education media

Proses Review : 18 - 31 Agustus 2020, Dinyatakan Lolos: 7 September 2020 


\section{PENDAHULUAN}

Ketoprak merupakan suatu seni pertunjukkan yang memadukan seni peran dan seni karawitan. Pertunjukan sebagai sarana menghibur dan sekaligus mempertahankan budaya masyarakat Jawa dengan menampilkan cerita yang mengemas kehidupan masyarakat Jawa.Cerita yang diusung oleh pertunjukkan ketoprak banyak mengandung pesan-pesan kehidupan yang penting dan berguna untuk karakter manusia. Menurut Lisbijanto (2013: 1) ketoprak merupakan teater rakyat yang menceritakan tentang kepahlawanan dan perjalanan hidup suatu keluarga kerajaan. Ketoprak sering dimainkan pada malam hari dengan durasi waktu antara 3 sampai 4 jam. Kostum yang dikenakan berupa pakaian daerah Jawa dan bahasa yang digunakan adalah bahasa Jawa. Cerita ketoprak banyak menceritakan tentang kehidupan masyarakat dan lingkungan kerajaan, bahkan cerita tersebut kadang kala menyinggung kekuasaan Belanda maupun Jepang yang menjajah bumi Nusantara yang dikemas dalam sebuah naskah.

Pertunjukkan ketoprak lakon Pedhut Jatisrana merupakan ketoprak yang memerankan naskah karya Bondan Nusantara dengan disutradarai oleh Dhimas Redhya Rahmawiyan serta dipentaskan oleh UKM Unit Pengembangan Kesenian Daerah (UPKD). Ketoprak lakon Pedhut Jatisrana merupakan salah satu pertunjukkan ketoprak yang mengangkat ceritanya berdasarkan naskah dari Bondan Nusantara. Ketoprak Pedhut Jatisrana dipentaskan di Teater Arena, Surakarta, Jawa Tengah tepatnya pada bulan Februari 2016. Pertunjukan ketoprak lakon Pedhut Jatisrana mengisahkan kehidupan keluarga yang penuh dengan permasalahan. Banendra yang merupakan tokoh utama dalam lakon Pedhut Jatisrana, mengatasi berbagai permasalahan dikeluarganya dengan keseriusannya dan penuh tanggung jawab. Sebagai salah satu contoh karakter Banendra yang ditunjukkan dengan sikap toleransi kepada Wirajaya, ayah Banendra ketika meninggalkan ibunya dan keluarganya. Karakter-karakter yang ditunjukkan oleh Banendra dapat dijadikan sebagai acuan untuk memperbaiki dan meningkatkan karakter pada masyarakat yang dapat dikatakan memprihatinkan.

Pendidikan karakter yang kuat sangat diperlukan saat ini untuk memperbaiki dan meningkatkan karakter masyarakat dengan menilik kasus dan peristiwa yang terjadi pada akhir-akhir ini. Adapun menurut Khasanah, Suyanto, dan Sudiyanto (2019: 173) bahwa salah satu cara untuk memperbaiki dan meningkatkan karakter di masyarakat yaitu dengan memperdalam pemahaman tentang seni dan budaya bangsa, yaitu karya sastra. Pendidikan karakter merupakan bagian dari pembelajaran yang baik dan merupakan bagian yang fundamental dari pendidikan yang baik (Kesuma, Triatna, Permana, 2013: 21). Moral dan karakter manusia saat ini dapat dikatakan kurang tertata dan terkesan menjurus ke arah negatif. Banyak kasus dan kejadian yang menunjukkan semakin rendahnya penera- pan nilai pendidikan karakter di masyarakat saat ini, yang banyak ditunjukkan oleh kalangan remaja. Adapun tujuan dari pendidikan karakter yaitu mengembangkan nilai-nilai yang terdapat pada Pancasila, meliputi, mengembangkan potensi remaja agar menjadi manusia berhati baik, berpikiran baik, dan berperilaku baik, membangun bangsa yang berkarakter Pancasila, dan mengembangkan potensi warga negara agar memiliki sikap percaya.

Menurut Hidayati, Zaim, Rukun, dan Darmansyah (2014: 189) terdapat 18 nilai pendidikan karakter yang terbagi menjadi, yaitu nilai religius, jujur, tanggung jawab, disiplin, kerja keras, kreatif, mandiri, rasa ingin tahu, demokratis, toleransi, menghargai prestasi, bersahabat, gemar membaca, cinta damai, peduli sosial, peduli lingkungan, semangat kebangsaan, cinta tanah air. Dapat disimpulkan bahwa pendidikan karakter sangat bermanfaat bagi remaja khususnya siswa untuk kehidupan sehari-hari. Selanjutnya, nilai-nilai tersebut diperkuat oleh penataan lingkungan dan kegiatan-kegiatan dilingkungan sekolah (Sudarajat, 2011: 47). Saat ini, banyak terdapat degradasi moral yang ditunjukkan dengan penyalahgunaan narkoba, seks bebas, kejahatan, dan perilaku negatif lain yang memprihatinkan (Agung, 2011: 392). Sebagai contoh dapat ditunjukkan dengan maraknya begal yang sangat mencemaskan masyarakat, kemudian kasus siswa yang berani mengancam guru dengan persoalan ditegur, serta maraknya kasus korupsi yang sangat menjamur.

Berdasarkan kasus dan permasalahan yang terjadi dan sangat memprihatinkan tersebut, memberikan suatu dorongan untuk mengkaji pertunjukkan ketoprak Pedhut Jatisrana sebagai sarana dan media pendidikan karakter pada masyarakat. Adapun penelitian ini dapat menambah pengetahuan masyarakat tentang pertunjukkan yang baik dan sarat akan pendidikan karakter.

\section{Perumusan Masalah}

Berdasarkan paparan latar belakang tersebut, dapat disimpulkan beberapa rumusan masalah sebagai berikut:

1. Apakah pertunjukkan ketoprak lakon Pedhut Jatisrana terdapat nilai pendidikan karakter?

2. Bagaimanakah nilai-nilai pendidikan karakter pada pertunjukkan ketoprak lakon Pedhut Jatisrana?

3. Mengapa pertunjukkan ketoprak lakon Pedhut Jatisrana dapat dijadikan sebagai media pendidikan karakter?

\section{Tujuan Penelitian}

Penelitian ini bertujuan untuk:

1. Mendeskripsikan dan menjelaskan pertunjukkan ketoprak lakon Pedhut Jatisrana terdapat nilai pendidikan karakter.

2. Mendeskripsikan dan menjelaskan nilai-nilai pendidikan karakter pada pertunjukkan ketoprak lakon Pedhut Jatisrana.

3. Menganalisis nilai-nilai pendidikan karakter pada per- 
tunjukkan ketoprak lakon Pedhut Jatisrana sebagai media pendidikan karakter.

\section{Kerangka Dasar Teori Ketoprak}

Kesenian ketoprak atau dalam bahasa Jawa sering disebut ketoprak adalah sebuah kesenian rakyat yang menceritakan tentang kisah-kisah kehidupan yang terjadi di jaman kerajaan. Kesenian ketoprak juga merupakan teater rakyat yang mengangkat kisah kepahlawanan dan perjalanan hidup keluarga kerajaan (Lisbijanto, 2013: 1). Sebuah pertunjukkan ketoprak dapat disebut ketoprak setelah ada unsur seni tari, seni suara, seni musik, dan seni akting di dalamnya. Adapun menurut Ensiklopedia Nasional Indonesia (1990: 51) dalam suatu pertunjukkan ketoprak, kostum yang dikenakan berupa pakaian daerah Jawa dan bahasa yang digunakan adalah bahasa Jawa. Cerita ketoprak pada saat itu banyak menceritakan tentang kehidupan masyarakat dan lingkungan kerajaan, bahkan cerita tersebut kadangkala menyinggung kekuasaan Belanda maupun Jepang yang menjajah bumi Nusantara ini.

Suatu pertunjukkaan ketoprak dipentaskan berdasarkan cerita yang sudah dituangkan penulisnya pada sebuah naskah sebagai suatu patokan dan gambaran. Adapun menurut Satoto (2012: 8) sebuah naskah dapat dikatakan baik jika ia kaya akan ide-ide baru, baik dilihat dari segi filsafat, kejiwaan, pendidikan, sosial, budaya, politik, ekonomi, pertahanan, keamanan, dan asli. Adapun naskah ketoprak adalah jenis karya sastra yang termasuk dalam genre teater atau drama tradisional Jawa (Setyawan, Saddhono, dan Rakhmawati, 2017: 144). Adapun penggambaran lakon ketoprak yang dituliskan melalui cerita dalam bentuk naskah oleh pengarang akan sedikit berbeda dari cerita teks aslinya. Hal ini dikarenakan daya imajinasi masing-masing pengarang berbeda sehingga di dalam menumpahkan ide karyanya yang berupa naskah ketoprak akan ditemui beberapa hal yang mungkin ditambahkan atau dikurangi, walaupun inti cerita masih sama dengan teks aslinya.

Pertunjukkan ketoprak merupakan pertunjukkan yang termasuk ke dalam golongan pertunjukkan drama. Pengertian tersebut dapat dikuatkan dengan terdapatnya serangkaian adegan pada pertunjukkan ketoprak yang dikemas menjadi sebuah cerita yang runtut. Adapun suatu drama yang baik merupakan drama yang banyak terdapat pesan moral dan nilai kehidupan yang berguna untuk kehidupan sehari-hari. Pertunjukkan ketoprak dapat juga berfungsi sebagai media komunikasi, media hiburan, media mempertahankan budaya, pendidikan, berdasarkan cerita yang ditampilkannya dan yang dipadukan dengan unsur musik dan unsur tari. Pesan atau nilai-nilai kehidupan yang terdapat pada pertunjukkan ketoprak dapat dijadikan sebagai media pendidikan karakter untuk masyarakat.

\section{Manfaat Penelitian \\ Manfaat Teoritis}

Penelitian ini diharapkan dapat menambah ilmu pengetahuan dan wawasan pembaca, khususnya pertunjukkan ketoprak yang terdapat nilai-nilai pendidikan karakter di dalamnya.

\section{Manfaat Praktis}

Bagi pendidik bahasa Jawa, penelitian ini diharapkan dapat menambah kekayaan ilmu pengetahuan dalam pembelajaran yang tepat dalam media pendidikan karakter agar dapat menambah minat siswa dalam media pendidikan karakter di sekolah.

Bagi peneliti lain, penelitian ini diharapkan dapat dijadikan bandingan bagi peneliti lain yang akan melakukan penelitian sastra dengan permasalahan yang sama dan sejenis.

Bagi masyarakat, penelitian ini diharapkan dapat memberikan referensi pertunjukkan yang sarat akan pendidikan karakter dan layak untuk ditonton oleh semua unsur masyarakat.

\section{METODE PENELITIAN}

Penelitian ini menggunakan bentuk penelitian deskriptif-kualitatif dengan metode analisis isi. Metode ini digunakan untuk menelaah isi dari dokumentasi video. Dokumentasi video dalam penelitian ini adalah video pertunjukkan ketoprak Pedhut Jatisrana di Taman Budaya Jawa Tengah. Pendeskripsian meliputi mencatat dan meneliti video pertunjukkan mengenai analisis nilai pendidikan karakter yang sesuai dengan ketetapan Kementerian Pendidikan Nasional dan relevan untuk media pendidikan karakter. Sumber data yang digunakan dalam penelitian ini, yaitu dokumentasi video. Dokumentasi video yang digunakan sebagai sumber data utama dalam penelitian ini adalah video ketoprak Pedhut Jatisrana. Teknik pengambilan subjek penelitian ini menggunakan purposive sampling. Teknik pengambilan sampel sumber data dengan pertimbangan tertentu (Sugiyono, 2012: 23). Purposive sampling adalah pemilihan sampel disesuaikan dengan masalah, kebutuhan, dan kemantaban peneliti dalam memperoleh data. Teknik pengumpulan data yang digunakan dalam penelitian ini yaitu analisis dokumentasi pertunjukkan ketoprak Pedhut Jatisrana. Adapun sebagai penguat analisis, menggunakan naskah, artikel dan buku yang berkaitan dengan penelitian ini. Teknik uji validitas data yang digunakan penulis adalah triangulasi. Triangulasi merupakan pengecekan data dari berbagai sumber dengan berbagai cara, dan berbagai waktu (Faruk dan Widada, 2017: 4). Teknik analisis data dalam penelitian ini menggunakan teknik analisis dialog dan gambar meliputi pengumpulan data, reduksi data, penyajian data, penarikan kesimpulan. Prosedur penelitian diawali dari tahap persiapan, tahap pelaksanaan, dan diakhiri dengan tahap penyusunan laporan. 


\section{ANALISIS DAN INTEPRETASI DATA}

Penelitian ini menggunakan analisis dialog dan analisis gambar yang terdapat pada video dokumentasi pertunjukkan ketoprak lakon Pedhut Jatisrana. Adapun nilai pendidikan karakter pada pertunjukkan ketoprak lakon Pedhut Jatisrana sebagai media pendidikan karakter sebagai berikut:

Dialog: "Haiya merga dadi pendhereke Njeng Pangeran kuwi simbok kuwatir. Kahanan ki jare saya panas, Nek ana apa apa piye, hayo?"

"Laiya karena jadi pengikut Pangeran itu Ibu khawatir. Keadaan saat ini katanya semakin memanas, kalau ada apa-apa bagaimana?" (terjemahan)

Dialog tersebut merupakan dialog antara Nyi Wirajaya dengan Banendra ketika Nyi Wirajaya sedang mengobrol dengan anaknya, Banendra, ketika tidak pulang kerumah selama 3 tahun. Adegan dan dialog tersebut apabila dikaji secara teliti terdapat nilai karakter peduli social. Peduli sosial merupakan suatu sikap selalu ingin memberi bantuan bagi orang lain dan masyarakat yang membutuhkan. Adapun karakter peduli sosial ditunjukkan dengan tokoh Nyi Wirajaya yang khawatir dengan keadaan anaknya ketika ikut perang dan ikut dengan Njeng Pangeran. Sifat dan sikap yang memang harus dimiliki seorang ibu dengan keadaan anaknya, keselamatan anaknya merupakan hal utama. Karakter yang ditunjukkan oleh Nyi Wirajaya dapat dijadikan suatu acuan dan tauladan bagi masyarakat dan khususnya orang tua dalam menjaga dan mendidik anak-anaknya di kehidupan sehari-hari. Adapun karakter peduli sosial yang ditunjukkan oleh tokoh Nyi Wirajaya juga relevan dan dapat dijadikan contoh untuk masyarakat luas agar selalu menanamkan sikap peduli dengan sesama manusia.

Dialog: “Cup, cup, aja nangis. Tak kandhani ya, aku ora mulih ki merga udan. Njur ngenteni terang. Karo maneh, aku neng kana ki rak merga arep ngabari si Tum nek bojone sing neng kutha lara napas, nek ora peneran isa bablas"

"Cup, cup, jangan menangis. Saya kasih tau, saya tidak pulang karena hujan. Kemudian menunggu reda, dan lagi, saya di sana karena mau mengabari Si Tum kalau suaminya yang merantau di Kota sakit napas, kalau tidak tertolong bisa meninggal" (terjemahan)

Dialog tersebut merupakan dialog antara tokoh Merta ketika sedang ditanya oleh istrinya, yaitu Gembyah, tentang kepulangannya ke rumah. Adegan dan dialog tersebut apabila dikaji dengan teliti, terdapat nilai karakter jujur yang ditunjukkan oleh tokoh Merta. Sikap jujur merupakan perilaku yang didasarkan pada upaya menjadikan dirinya sebagai orang yang selalu dapat dipercaya dalam perkataan, tindakan, dan pekerjaan, baik terhadap diri dan pihak lain. Kejujuran diri merupakan suatu ukuran kepribadi- an yang penting dalam kehidupan sehari-hari (Kajonius, 2014: 2). Adapun Merta mengatakan dengan jujur ketika ditanya oleh istrinya, bahwa dirinya menunggu hujan reda dan mengabari si Tum tentang keadaan suaminya. Karakter jujur yang dimiliki tokoh Merta,bisa dijadikan acuan sebagai media pendidikan karakter di masyarakat umum yang kurang menjunjung nilai kejujuran.

Dialog: "Alah-alah yo sokur. Kabeh wis bali rukun. Merga nek para luhur sulaya gedhene perang kuwi sing cilaka rak wong cilik ta?"

"Alah-alah ya syukur. Semua sudah rukun, karena kalau para penguasa perang, yang susah dan celaka itu kan rakyat kecil to?" (terjemahan)

Dialog tersebut merupakan dialog antara Nyi Wirajaya dengan anaknya, yaitu Banendra saat menanyakan tentang kehidupan Banendra semasa ikut dengan Kanjeng Pangeran Perang. Adegan dan dialog tersebut apabila dikaji dengan teliti, terdapat nilai karakter cinta damai yang ditunjukkan dengan tokoh Nyi Wirajaya yang bersyukur ketika perang sudah reda dan dirinya lebih suka ketika hidup rukun. Cinta damai merupakan sikap dan tindakan yang mencerminkan suasana aman, damai, dan nyaman dalam masyarakat. Karakter cinta damai yang ditunjukkan oleh tokoh Nyi Wirajaya dapat dijadikan contoh dan acuan sebagai media pendidikan karakter dalam memperbaiki karakter masyarakat saat ini yang dapat dikatakan dengan kurangnya cinta damai pada diri masyarakat.

Dialog: "Orak, simbok tak takon. Sakjrone kowe lunga rak ya durung entuk bojo to le? Sapa? Pilihanmu sapa le? Bocahe ayu ora?"

"Tidak, Ibu tanya. Selama kamu pergi belum juga dapat istri to Nak? Siapa? Pilihanmu siapa Nak? Anaknya cantik tidak?" (terjemahan)

Kutipan dialog tersebut merupakan dialog antara Nyi Wirajaya dengan anaknya, Banendra. Dirinya menanyakan kepada Banendra tentang wanita yang akan hidup bersama Banendra. Adegan dan dialog tersebut apabila dikaji dengan teliti, terdapat nilai karakter rasa ingin tahu yang ditunjukkan oleh Ibu Banendra, yaitu Nyi Wirajaya. Sikap rasa ingin tahu merupakan sikap dan tindakan yang selalu berupaya untuk mengetahui lebih mendalam dan meluas dari apa yang dipelajarinya, dilihat, dan didengar. Karakter rasa ingin tahu dapat dijadikan suatu acuan dan contoh untuk para masyarakat, khususnya para pelajar yang bisa menerapkan karakter rasa ingin tahu dalam suatu pembelajaran. Pastinya, karakter rasa ingin tahu sangat penting dan berguna dalam pembelajaran, ketika ada hal yang belum dipahami oleh seorang pelajar, bisa menanyakan kepada guru.

Dialog: "Senajan aku cah ndesa, ning ajiku le dadi manungsa padha karo kowe, karo simbok lan kakang Panuntun! Nek ana manungsa sing ora nguwongke manungsa, 
kayangana kuwi tegese ngelanggar paugerane sing Gawe Urip!'

"Walaupun saya anak desa, tapi saya manusia seperti dengan anda, dengan Ibu dan kakak saya, Panuntun! Kalau ada manusia yang tidak memanusiakan manusia, seperti itu namanya melanggar aturan Gusti!" (terjemahan)

Kutipan dialog tersebut merupakan dialog antara Banendra dengan Panuntun, kakaknya. Dialog tersebut apabila dikaji dengan teliti, terdapat nilai karakter religius yang ditunjukkan oleh tokoh Banendra ketika mengobrol dengan kakaknya, Panuntun. Religius merupakan suatu pikiran, perkataan, dan tindakan yang dilakukan seseorang dalam kehidupan sehari-harinya diupayakan selalu berdasarkan pada nilai-nilai Ketuhanan dan wujud rasa syukur atas nikmat yang dilimpahkan Tuhan kepada umat manusia (Puwaningtyas dan Kuswarsantyo, 2018: 189).. Adapun Banendra menyatakan bahwa derajat semua manusia sama dimata sang pencipta. Adapun sesama manusia saling menghargai dan menghormati satu sama lain. Karakter religius yang dimiliki Banendra bisa dijadikan acuan dalam peningkatan dan pengembangan karakter di masyarakat, bilamana di zaman saat ini sikap menghargai dan menghormati manusia satu sama lain dapat dikatakan kurang, apalagi ketika strata sosial masyarakat berkebutuhan cukup dan lebih kepada masyarakat berkebutuhan kurang.

Dialog: "Aku kudu melu-melu! Luput gedhe yen aku mung bandha tangan weruh Jatisrana dirusak wong-wong sing gawe pernatan ana ing sakjroning pernatan, gelem semingkir nek wis klakon ngringkus kowe sak kanca".

"Aku harus ikut campur! Salah besar kalau saya hanya berdiam diri melihat Jatisrana diserang oleh orang-orang yang membuat masalah di dalam masalah, aku akan minggir kalau sudah berhasil meringkusmu dan teman-temanmu!" (terjemahan)

Kutipan dialog tersebut merupakan dialog antara Banendra dengan Surogobang dan grayak-grayak ketika akan menyerang daerahnya. Dialog yang terdapat pada adegan tersebut terdapat nilai karakter cinta tanah air yang ditunjukkan oleh tokoh Banendra ketika daerahnya dan tanah kelahirannya akan diserang oleh Suragobang dan teman-temannya. Sikap cinta tanah air merupakan cara berpikir, bersikap dan berbuat yang menunjukan kesetiaan, kepedulian, dan penghargaan yang tinggi terhadap bangsa, lingkungan fisik, sosial, budaya, ekonomi, dan politik bangsanya. Karakter cinta tanah air yang dimiliki tokoh Banendra dapat dijadikan contoh dan acuan untuk masyarakat agar lebih menanamkan rasa cinta tanah air pada diri sendiri terhadap tanah air.

Dialog: “Wis, arep piye kowe saiki? Njaluk urip apa mati? "Aku njaluk urip! Aku aja kok pateni."

"Sudah, maumu bagaimana sekarang? Minta hidup apa mati?

"Saya minta hidup! Saya jangan dibunuh." (terjemahan)
Kutipan dialog tersebut merupakan dialog antara Banendra dengan Surogobang dan anak buahnya. Percakapan tersebut merupakan percakapan yang terjadi ketika Banendra selesai berperang dan tempur dengan Surogobang beserta teman-temannya. Apabila dicermati dengan cermat, dialog tersebut terdapat muatan karakter kerja keras yang ditunjukkan oleh tokoh Banendra. Sikap kerja keras merupakan perilaku yang menunjukan upaya sungguh-sungguh dalam mengatasi berbagai hambatan guna menyelesaikan permasalahan atau tugas (belajar atau pekerjaan) dengan sebaik-baiknya. Dirinya hanya seorang diri menghadapi Surogobang dan temannya-temannya, kemudian berhasil meringkusnya dan melindungi Jatisrana tetap utuh. Adapun karakter kerja keras yang ditunjukkan oleh tokoh Banendra tersebut dapat dijadikan acuan dan contoh untuk para masyarakat, khususnya para remaja, untuk selalu menjunjung jiwa kerja keras dalam segala hal agar mendapatkan suatu hasil yang maksimal. Terlebih karakter kerja keras yang ditunjukkan oleh tokoh Banendra tersebut relevan dengan masalah pengangguran saat ini yang sangat memprihatinkan.

\section{SIMPULAN}

Berdasarkan analisis dan pembahasan yang sudah diuraikan di atas, pertunjukkan ketoprak lakon Pedhut Jatisrana terdapat nilai pendidikan karakter yang berguna dan relevan sebagai media pendidikan karakter pada masayarakat. Beberapa dialog dan adegan yang terdapat pada pertujukkan Pedhut Jatisrana menunjukkan adanya beberapa nilai karakter yang sesuai dengan kajian penelitian ini. Adapun nilai karakter yang terdapat pada pertunjukkan ketoprak Pedhut Jatisrana yaitu diantaranya nilai karakter cinta tanah air, religius, rasa ingin tahu, jujur, peduli sosial, kerja keras dan nilai karakter cinta damai yang terdapat pada beberapa adegan dan dialog. Adapun tokoh yang terdapat pada lakon tersebut yang dapat dijadikan sebagai acuan dan contoh dalam mengembangkan pendidikan karakter yaitu tokoh Banendra yang memiliki karakter-karakter panutan.

Adapun pertunjukkan ketoprak lakon Pedhut Jatisrana tersebut dapat dijadikan referensi tontonan pada kalangan masyarakat, khususnya para remaja, sebagai suatu tontonan yang sarat akan muatan pendidikan karakter untuk meningkatkan karakter pada masyarakat yang dapat dikatakan saat ini memprihatinkan.

\section{DAFTAR RUJUKAN}

A. Sudrajat. "Mengapa Pendidikan Karater". Jurnal Pendidikan Karakter, Volume 1, Nomor 1, 2011 pp. 47-58.

Agung. "Character Education Integrating in Social Studies Learning". International Journal of History Education, Volume 12, Nomor 2, 2011 pp. 392-403. 
_Bagus, W.S., Kundharu, S., Ani R. "Sociological Aspect and Local Specificity in the Classical Ketoprak Script of Surakarta Style". Journal of Languange and Literature, Volume 17, Nomor 2, 2017 pp. 144-151.

Faruk, Widada. (2017). Metode Penelitian Sastra: Sebuah Penjelejahan Awal. Pustaka Pelajar, Yogyakarta.

Hidayati, A., Zaim, M., Rukun, K., Darmasnyah. "The Development of Character Education Curriculum for Elementary Student in West Sumatra”. International Journal of Education and Research, Volume 2, Nomor 6, 2014 pp. 189-198.

Kajonius, P.J, Daderman, A.M. "Honesty-Humility and Liberal Values". Journal of Psychology. Volume 10, Nomor 1, 2014 pp. 1-15.

Kesuma, D., Triatna, C., \& Permana, J. (2013). Pendidikan Karakter Kajian Teori dan Praktik di Sekolah. Remaja Rosdakarya, Bandung.

Khasanah, M., Suyanto, S., \& Sudiyanto, S. (2019). Nilai Pendidikan Karakter pada Wangsalan Sindhenan Karya Nyi Bei Mardusari. Mudra Jurnal Seni Budaya, 34(2), 172-176. https://doi.org/10.31091/mudra.v34i2.666

Lisbijanto. (2013). Ketoprak. Graha Ilmu, Yogyakarta.

Purwaningtyas, Kuswarsantyo. (2018). Nilai Pendidikan Karakter Dalam Ragam Gerak Tari Srimpi Pandelori. Mudra Jurnal Seni Budaya, 33(2), 182-190. https://doi. org/10.31091/mudra.v33i2.329

Satoto, Soediro. (2012). Analisis Drama dan Teater Jilid I. Penerbit Ombak, Yogyakarta.

Sugiyono. (2012). Metode Penelitian Pendidikan. Alfabeta, Bandung. 